\title{
Effectiveness of Internet-Delivered Computerized Cognitive Behavioral Therapy for Patients With Insomnia Who Remain Symptomatic Following Pharmacotherapy: Randomized Controlled Exploratory Trial
}

Daisuke Sato ${ }^{1,2}$, OTR, PhD; Naoki Yoshinaga ${ }^{3}$, RN, PhD; Eiichi Nagai ${ }^{4}$, PharmD; Kazue Nagai ${ }^{5}$, PhD; Eiji Shimizu ${ }^{1,6,7}$, $\mathrm{MD}, \mathrm{PhD}$

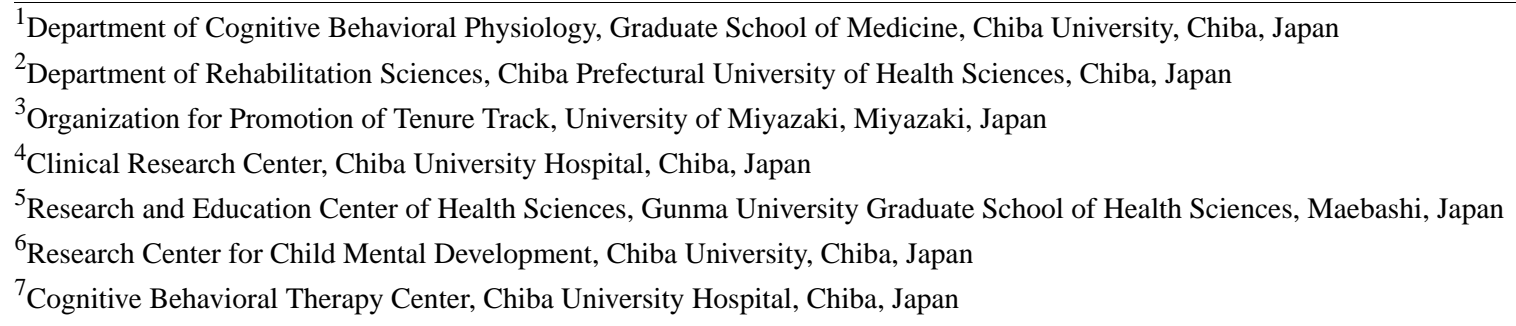

\section{Corresponding Author:}

Daisuke Sato, OTR, PhD

Department of Cognitive Behavioral Physiology

Graduate School of Medicine

Chiba University

$1-8-1$

Inohana, Chuo-ku

Chiba, 260-8670

Japan

Phone: 81432262027

Fax: 81432262028

Email: daisuke-sato@umin.ac.jp

\section{Abstract}

Background: In reality, pharmacotherapy still remains the most common treatment for insomnia.

Objective: This study aimed to examine the effectiveness of our internet-delivered computerized cognitive behavioral therapy (ICBT) program as an adjunct to usual care (UC) compared with UC alone in patients with insomnia who remain symptomatic following hypnotics.

Methods: We recruited 23 patients with insomnia who remained symptomatic following pharmacologic treatment including benzodiazepines, and we conducted an exploratory randomized controlled trial. The primary outcome was the Pittsburgh Sleep Quality Index (PSQI) at week 6 of the treatment. Secondary outcomes were sleep onset latency, total sleep time, sleep efficiency, number of awakenings, refreshment and soundness of sleep, anxiety by Hospital Anxiety and Depression Scale, depression measured by the Center for Epidemiologic Studies Depression Scale, and quality of life (QOL) measured by the EuroQol-5D. All parameters were measured at weeks 0 (baseline), 6 (postintervention), and 12 (follow-up).

Results: The adjusted mean reduction (-6.11) in PSQI at week 6 from baseline in the ICBT plus UC group was significantly $(P<.001)$ larger than the adjusted mean reduction $(0.40)$ in the UC alone group. Significant differences were also found in favor of ICBT plus UC for PSQI, sleep onset latency, sleep efficiency, number of awakenings, and depression at all assessment points. Refreshment, soundness of sleep, anxiety, and QOL improved by week 6 in ICBT plus UC compared with UC alone. There were no reports of adverse events in either group during the study.

Conclusions: These results indicated that our 6-week ICBT program is an effective treatment adjunct to UC for improving insomnia and related symptoms even after unsuccessful pharmacotherapy. 
Trial Registration: University Hospital Medical Information Network Clinical Trials Registry: UMIN000021509; https://upload.umin.ac.jp/cgi-open-bin/ctr_e/ctr_view.cgi?recptno=R000023545 (Archived by WebCite at http://www.webcitation. org/75tCmwnYt).

(J Med Internet Res 2019;21(4):e12686) doi: 10.2196/12686

\section{KEYWORDS}

insomnia; cognitive behavioral therapy; randomized controlled trial; internet; benzodiazepines; residual symptoms

\section{Introduction}

\section{Background}

Insomnia, which affects $10 \%$ to $12 \%$ of the total population, is characterized by the inability to fall asleep or awakening too early in the morning or during the night, resulting in nonrestorative sleep and decreased daytime functioning [1-4]. The spontaneous improvement of insomnia is low [5]. The treatment options for insomnia are psychotherapy and pharmacotherapy, and the American College of Physicians (ACP) recommends that all adult patients receive cognitive behavioral therapy (CBT) for insomnia as the initial treatment for chronic insomnia disorder. The ACP also recommends that clinicians use a shared decision-making approach, including a discussion with the patient, of the benefits, harms, and costs of the short-term use of medications before deciding whether to add pharmacological therapy in adults with chronic insomnia disorder in whom CBT for insomnia alone was unsuccessful [6]. In 2005, Vallières et al reported that pharmacotherapy before the initiation of CBT appears to be less effective than the combined treatment of pharmacotherapy plus CBT, followed by CBT alone [7]. Their study also revealed that the early introduction of CBT contributes to a maximization of the effect of pharmacotherapy.

Pharmacotherapy remains the most commonly used treatment option for insomnia worldwide [8]. In Japan, especially, CBT for insomnia is not covered by public health insurance at this time (2018), and thus the most common initial treatment for insomnia is a primary care physician's prescription of an insomnia drug such as a benzodiazepine, nonbenzodiazepine, orexin receptor antagonist, or melatonin receptor agonist and antidepressants [9]. Although pharmacotherapy is associated with a high incidence of adverse effects including daytime sleepiness, recurrent insomnia, and drug dependence [10], physicians in Japan often prescribe excess doses of benzodiazepine [11]. A next step treatment in patients with insomnia who remain symptomatic following pharmacotherapy is strongly needed. Clinical practice guidelines suggest CBT, rather than pharmacotherapy, as the initial therapy for patients with insomnia $[6,12,13]$. Okajima et al showed that face-to-face CBT with a behavioral analysis is more effective than pharmacotherapy for Japanese chronic insomnia patients who are resistant to pharmacological treatment [14]. As Web-based programs are now more accessible and low cost and can be conveniently completed at one's own time and place [15], we have developed an internet-delivered computerized cognitive behavioral therapy (ICBT) program for insomnia and we published a randomized controlled trial (RCT) design [16].

\section{Objectives}

We conducted the RCT to examine the effectiveness of ICBT as an adjunct to usual care (UC) compared with UC alone, specifically targeting insomnia patients who remain symptomatic after pharmacotherapy. We hypothesized that among insomnia patients who remain symptomatic after pharmacotherapy, the augmentation with ICBT would be superior to UC alone in improving overall sleep quality, reducing anxiety and depression, and improving the patients' quality of life (QOL).

\section{Methods}

\section{Study Design and Participants}

Our study protocol has been published [16] and is therefore only summarized here. This was a randomized controlled single-center trial conducted at the academic outpatient clinic of the Cognitive Behavioral Therapy Center of Chiba University Hospital between March 2016 and January 2018 as the recruitment period and between March 2016 and April 2018 as the trial period. Participants were recruited through posters and leaflets placed at medical institutions in the Chiba prefecture and through Web-based and newspaper advertisements. The inclusion criteria for this study were as follows: the participant regularly went to bed between 8 pm and 2 am; aged 18 to 65 years; having a primary diagnosis of insomnia according to the Diagnostic and Statistical Manual of Mental Disorders, Fifth Edition [1]; and the aforementioned insomnia remaining symptomatic. Remaining symptomatic was defined herein as having insomnia that is at least moderate in severity, based on a Pittsburgh Sleep Quality Index (PSQI) score of greater than $5.5[15,17,18]$ after the use of hypnotics including nonbenzodiazepines, benzodiazepines, melatonin receptor agonists, orexin receptor antagonists, and antidepressants.

Each participant's treatment history was confirmed by their prescribing clinician and by chart review. All patients were evaluated by 2 researchers (a psychiatrist, ES, and a therapist, DS) who also verified the patient diagnosis and eligibility. They discussed the validity of the patient's initial diagnosis and eligibility. Patients were reevaluated to cover important missing information based on suggestions derived from the discussion, and the final diagnosis and eligibility were confirmed by the 2 researchers.

The exclusion criteria included severe symptoms of anxiety or depression. Anxiety was assessed using the anxiety subscale of the Hospital Anxiety and Depression Scale (HADS) which contains 7 items. Depression was assessed using the total score of the Center for Epidemiological Studies Depression (CES-D) scale. Patients with a HADS score of greater than or equal to 10 or a CES-D score of greater than or equal to 30 were 
excluded. Patients with psychosis, organic mental disorder, or current high risk of suicide, substance abuse, or dependence within the 12 months before enrollment, antisocial personality disorder, or unstable medical condition were also excluded.

\section{Randomization}

At the end of the baseline assessment, eligible participants were randomly assigned to either the UC arm or ICBT plus UC arm at a ratio of $1: 1$, with assignments made using the minimization method, ensuring a balance in baseline PSQI scores (PSQI $<12$ ) and gender. Each participant was then assigned to one of the 2 treatment regimes. Participants were blinded to the group to which they were assigned before consenting to participate in the study.

\section{Procedures}

Primary physicians referred patients to the trial but continued to provide pharmacotherapy as UC to the patients in both groups, as described $[19,20]$. As part of the UC, both the UC only and ICBT plus UC groups received email magazines with general information about insomnia and hypnotics (in PDF format) by our research team 4 times over a 6 -week period.

The ICBT program for insomnia was developed by one of the authors (ES) and is named the Insomnia Improvement Internet Program. The program is called IIIP (pronounced three $P$ ) for short, as III indicates the Roman numeral and three $P$ sounds like sleepy.

The ICBT treatment consists of 5 weekly lessons and includes various elements that are commonly incorporated in face-to-face CBT for insomnia as follows: (1) keeping a sleep diary and understanding sleep hygiene; (2) changing sleep-related behaviors, including stimulus control; (3) restructuring distorted beliefs about sleep and sleep-related worries; (4) sleep restriction to increase sleep efficiency(SE); and (5) relaxation training, including breathing exercises and progressive muscle relaxation. Participants completed the 5 lessons over a 6-week period to provide sufficient time to become accustomed to the CBT. One of the authors (DS), a cognitive behavioral therapist, sent weekly emails to the participants to ask them about their homework and progress. The intervention was implemented as a cognitive behavioral therapist supported ICBT. Participants in the control group were offered the ICBT after the trial, if the UC did not make them sleep better.

\section{Outcomes}

\section{Primary Outcome}

The primary outcome was the change in the PSQI score at week 6 from baseline (week 0). The PSQI is a self-rated questionnaire consisting of 19 questions across 7 subscales (sleep quality, sleep latency, sleep duration, habitual sleep efficiency, sleep disturbance, use of hypnotics, and daytime dysfunction). Each subscale is scored on a scale of 0 to 3 . Subscale scores are summed to a total score ranging from 0 (good quality of sleep) to 21 (very poor quality of sleep). The PSQI was verified as a reliable and valid measure of subjective sleep quality in clinical practice and experimental research $[17,18]$.

\section{Secondary Outcomes}

The secondary outcomes included the change in the PSQI score at week 3 and at week 12 from baseline (week 0) and the sleep onset latency (SOL), total sleep time (TST), SE, and number of awakenings (NA) extracted from the PSQI, as well as the current feeling of refreshment, perceived soundness of sleep (assessed by a visual analog scale), the anxiety subscale of HADS measuring anxiety, the CES-D score measuring depression, and EuroQol-5D (EQ-5D) score measuring the participant's QOL [21].

The total score on the 7 HADS anxiety subscale items ranges from 0 (no symptoms of anxiety) to 21 (severe symptoms of anxiety). The total score on the 20 CES-D items ranges from 0 (no symptoms of depression) to 60 (severe symptoms of depression). We have described the 3-level version of the EQ-5D [21]. The EQ-5D [21] contains 5 items that assess QOL on a 3 -point Likert scale ranging from 1 (not severe) to 3 (severe). The Japanese version of the EQ-5D was developed by Tsuchiya et al [22]. The EQ-5D is the most commonly used scale worldwide for calculating quality-adjusted life years (QALYs). QALYs are often used as the health outcome in cost-utility analyses and are typically estimated via an area under the curve analysis which involves summing the areas of the distribution shapes to calculate utility scores over the study period $[23,24]$. Our participants completed the HADS, CES-D, and EQ-5D questionnaires at home and sent them to us by email.

The therapist asked the participants about adverse event experiences at each assessment. All measures were assessed at weeks 0 (baseline), 3 (midintervention), 6 (postintervention), and 12 (follow-up).

\section{Statistical Analyses}

The statistical analyses and reporting of this trial were conducted in accordance with the Consolidated Standards of Reporting Trials (CONSORT) guidelines. For baseline variables, summary statistics were constructed, using frequencies and proportions for categorical data and the mean and SD for continuous variables. Baseline variables were compared using Fisher exact test for categorical outcomes and the unpaired $t$ test for continuous variables. For the primary analysis comparing treatment effects, the least-squares means, and their 95\% CIs were estimated by an analysis of covariance (ANCOVA) with the change in total PSQI scores at week 6. This ANCOVA model took into account the variation caused by treatment effects, and the participants' gender and baseline PSQI score were entered as covariates. Analyses of secondary outcomes were performed in the same manner as the primary analysis. All $P$ values were 2 -sided. $P$ values less than .05 were considered significant. All statistical analyses were performed using SAS version 9.4 software (SAS Institute).

As described by our published design study [16], the sample size was based on a previous study by van Straten et al [25], which indicated that the estimated group difference in changes of PSQI scores from baseline was approximately 2.86 (ICBT group $=3.00$; control group $=0.04$ ). Assuming a group difference of 2.86 points (SD 2.5), 13 subjects per group will provide $80 \%$ power to detect a difference in PSQI scores between the UC 
arm and ICBT plus UC arm, using a 2-sided, 2-sample $t$ test at a $5 \%$ significance level. Thus, allowing for a $10 \%$ dropout rate, 15 participants are required per group, for a total of 30 participants in the study.

\section{Ethical Approval}

Written informed consent was obtained from all patients after the procedures had been fully explained. Ethical approval was obtained from the Institutional Review Board of Chiba University Hospital (no. G27040), and the trial was registered as UMIN000021509.

\section{Results}

\section{Recruitment}

Figure 1 shows the patient recruitment flow diagram, based on the CONSORT guidelines. A total of 32 patients applied to participate through our website. Of the 9 patients who were excluded, 4 did not meet one of the inclusion criteria because of their age (over the limit) and 5 declined to participate because of the long distance to our hospital. A final total of 23 patients attended the face-to-face baseline assessment, and all 23 were enrolled in the study. We randomly assigned the 23 patients to the ICBT plus UC and UC groups. Furthermore, 1 patient in the UC group declined to continue to participate and dropped out from the study after the assessment at week 6 . Though the originally planned recruitment rate would be 2 participants per month, the real average recruitment rate was 1 participant per month through posters and leaflets placed at medical institutions in the Chiba prefecture and through Web-based and newspaper advertisements within the planned recruitment period between March 2016 and January 2018. We had to stop recruitment after we entered 23 patients after 23 months of trial commencement on the closing date (see Figure 1).

Figure 1. The CONSORT flow diagram for the trial. ICBT: internet-delivered computerized cognitive behavioral therapy; UC: usual care.

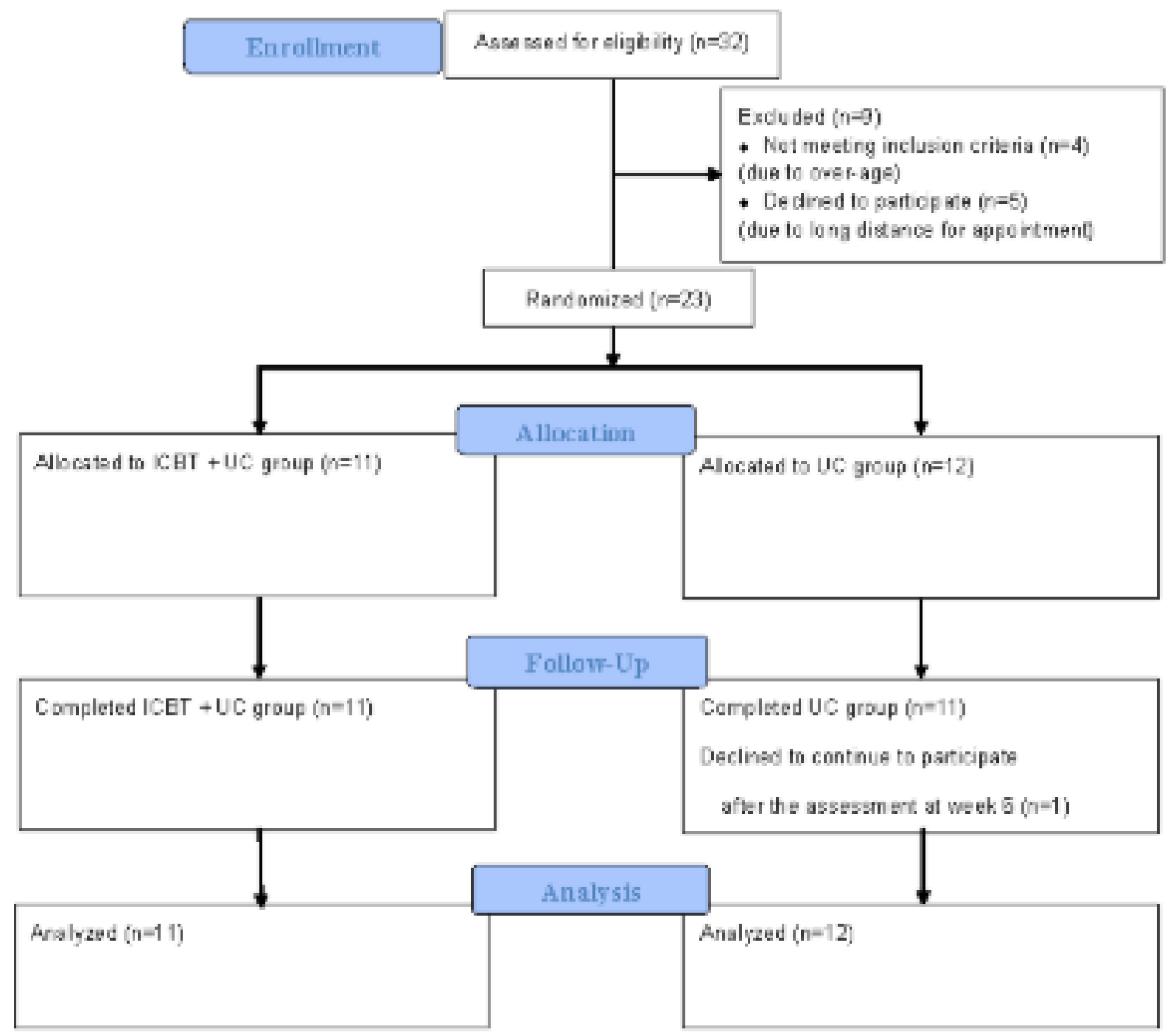

\section{Demographics and Clinical Characteristics}

Table 1 summarizes the baseline demographic and clinical characteristics of the participants. There were no significant between-group differences in any of the characteristics, including the number of patients with a baseline PSQI score less than $12(\mathrm{PSQI}<12)$ and the total PSQI score. The ICBT plus UC group received pharmacologic treatment including 
zolpidem $(n=3)$, brotizolam $(n=2)$, eszopiclone $(n=1)$, etizolam $(n=1)$, estazolam $(n=1)$, flunitrazepam $(n=1)$, alprazolam $(n=1)$, and the combined use of zolpidem and brotizolam $(n=1)$. The UC group received pharmacologic treatment including zolpidem $(n=3)$, brotizolam $(n=2)$, zopiclone $(n=1)$, etizolam $(n=1)$, the combined uses of zolpidem and etizolam $(\mathrm{n}=1)$; lormetazepam and flunitrazepam $(\mathrm{n}=1)$; quazepam and lorazepam $(\mathrm{n}=1)$; brotizolam, nitrazepam, and clonazepam $(n=1)$; and zolpidem, lormetazepam, and trazodone hydrochloride $(\mathrm{n}=1)$. Thus, all 23 of the participants were taking one or more benzodiazepines. There was no change of use of sleep medication during intervention and follow-up period among the ICBT plus UC and UC group patients. We are conducting further study to estimate a difference in reduced use of sleep medication after the end of the follow-up period among the ICBT plus UC and UC group patients.

Table 1. Baseline characteristics ( $\mathrm{N}=23)$.

\begin{tabular}{lll}
\hline Variable & $\mathrm{ICBT}^{\mathrm{a}}+\mathrm{UC}^{\mathrm{b}}(\mathrm{n}=11)$ & $\mathrm{UC}(\mathrm{n}=12)$ \\
\hline Female, $\mathrm{n}(\%)$ & $9(81.8)$ & $9(75.0)$ \\
Age in years, mean (SD) & $49.4(13.8)$ & $50.5(8.8)$ \\
Material status (married of living as married), $\mathrm{n}(\%)$ & $9(81.8)$ & $10(83.3)$ \\
Length of education in years, mean (SD) & $14.1(2.5)$ & $14.5(1.9)$ \\
Employment status (in paid employment, full or part-time), $\mathrm{n}(\%)$ & $9(81.7)$ & $9(75.0)$ \\
Alcohol drinking (habitual or opportunity drinking), $\mathrm{n}(\%)$ & $3(27.3)$ & $7(58.3)$ \\
Smoking, $\mathrm{n}(\%)$ & $0(0)$ & $6.3(0)$ \\
Duration of insomnia in years, mean (SD) & $3(27.3)$ & $3(25.0)$ \\
Number of patients with PSQI ${ }^{\mathrm{c}}$ less than 12, $\mathrm{n}(\%)$ & & $6.1)$ \\
\hline
\end{tabular}

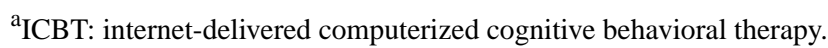

${ }^{\mathrm{b}} \mathrm{UC}$ : usual care.

${ }^{\mathrm{c}}$ PSQI: Pittsburgh Sleep Quality Index.

\section{Primary Outcome}

The raw data (ie, mean and SDs) of the participants' PSQI scores at the 4 assessment points are shown in Figure 2 and Table 2. At week 6, the adjusted mean reductions in PSQI from baseline were $-6.11(95 \% \mathrm{CI}-7.45$ to -4.78$)$ and $0.40(95 \% \mathrm{CI}-0.83$ to 1.63$)$ for the ICBT plus UC and UC groups, respectively. The group difference was significant at -6.51 (95\% CI -8.15 to $4.87, P<.001$; Table 3 ). The combination therapy, that is, ICBT plus UC, was therefore superior to UC alone.

\section{Secondary Outcomes}

At week 3, the adjusted mean reductions in PSQI from baseline were -2.66 (95\% CI -3.63 to -1.69$)$ and 0.45 (95\% CI -0.45 to 1.34 ) for the ICBT plus UC and UC groups, respectively. The group difference was significant at -3.10 (95\% CI -4.29 to $1.92, P<.001$; Table 3$)$. At week 12 , the adjusted mean reductions in PSQI from baseline were -6.40 (95\% CI -8.05 to -4.75$)$ and 0.44 (95\% CI -1.11 to 1.99$)$ for the ICBT plus $\mathrm{UC}$ and UC groups, respectively. The group difference was significant at -6.84 (95\% CI -8.90 to $4.77, P<.001$; Table 3 ). The combination therapy of ICBT plus UC was thus superior to $\mathrm{UC}$ alone at all 3 of the assessment time points.
The raw data (mean and SDs) and the adjusted mean changes for the secondary outcome measures are presented in Table 2 and Table 3, respectively. At week 3, compared with the UC group, significant improvements were observed in the ICBT plus UC group in the SOL, SE, NA scores, and CES-D (all $P<.05)$. At week 6 , compared with the UC group, significant improvements were observed in the ICBT plus UC group in the SOL, SE, NA, current feeling of refreshment, perceived soundness of sleep, the anxiety subscale of HADS, the CES-D, and the EQ-5D (all $P<.05$ ). At week 12, compared with the UC group, significant improvements were observed in the ICBT plus UC group in SOL, SE, NA, current feeling of refreshment, perceived soundness of sleep, the anxiety subscale of HADS, the CES-D, and the EQ-5D (all $P<.05$ ). There were no significant differences in the TST between the 2 groups at the 3 time points.

This result shows that, compared with the insomnia patients who received only UC, those who received ICBT plus UC reported significant improvements in their current feeling of refreshment, perceived soundness of sleep, measures of anxiety and depression, and functioning or QOL improved by week 6 . The administration of ICBT improved the SOL, SE, NA, and depression at an early stage, but not the TST at the final stage. 
Figure 2. Mean and SDs (raw data) for the primary outcome, the Pittsburgh Sleep Quality Index (PSQI) score improvement. ICBT: internet-delivered computerized cognitive behavioral therapy; UC: usual care.

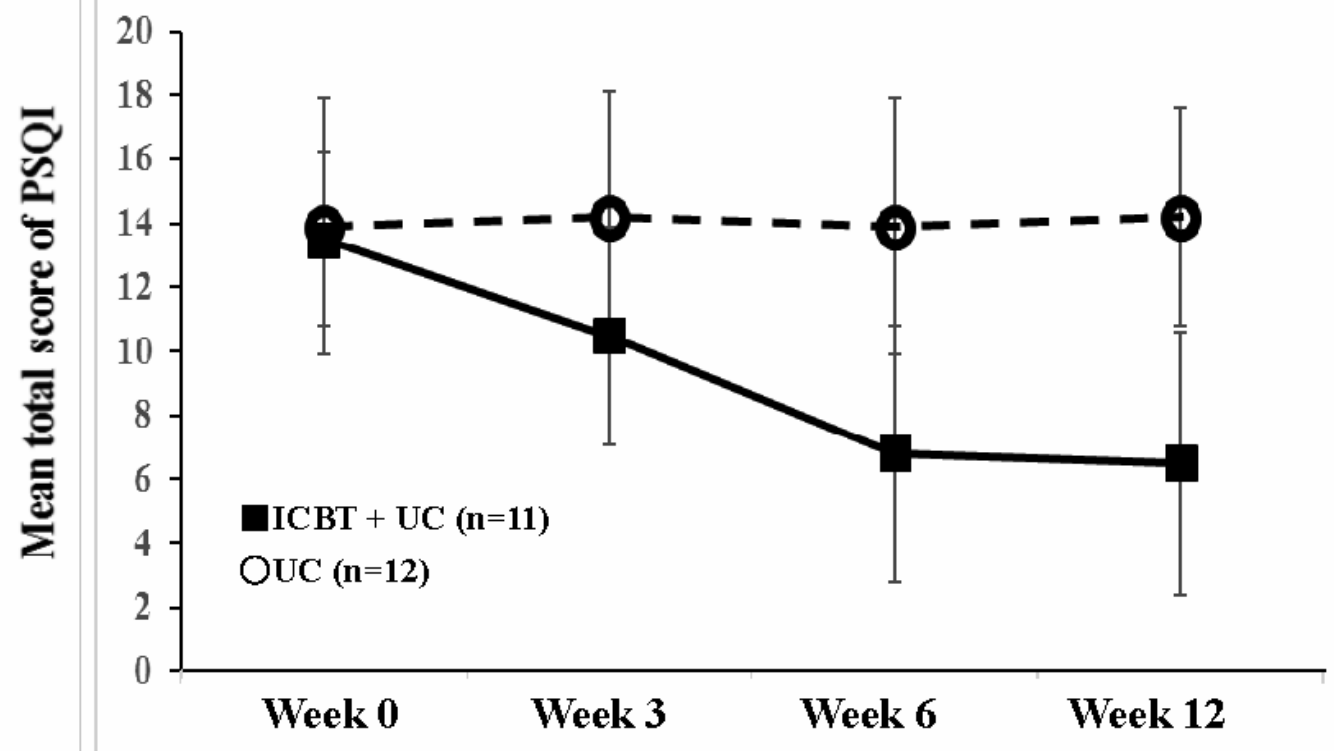

Table 2. Raw data of the primary and secondary outcomes $(\mathrm{N}=23)$.

\begin{tabular}{|c|c|c|}
\hline Variable & $\mathrm{ICBT}^{\mathrm{a}}+\mathrm{UC}^{\mathrm{b}}(\mathrm{n}=11)$ & $\mathrm{UC}(\mathrm{n}=12)$ \\
\hline \multicolumn{3}{|l|}{ Primary outcome: sleep characteristics } \\
\hline $\mathrm{PSQI}^{\mathrm{c}}$, mean $(\mathrm{SD})$ & $13.5(2.7)$ & $13.9(4.0)$ \\
\hline \multicolumn{3}{|l|}{ Secondary outcomes: sleep } \\
\hline $\mathrm{SOL}^{\mathrm{d}}$, minute, mean (SD) & $54.5(43.4)$ & $41.7(20.7)$ \\
\hline $\mathrm{TST}^{\mathrm{e}}$, hour, mean (SD) & $6.3(2.1)$ & $5.9(1.2)$ \\
\hline Sleep efficiency, $\%$, mean (SD) & $73.2(8.4)$ & $73.6(20.6)$ \\
\hline $\mathrm{NA}^{\mathrm{f}}$, mean $(\mathrm{SD})$ & $3.5(2.9)$ & $2.9(1.7)$ \\
\hline Refreshment, mean (SD) & $3.8(2.6)$ & $4.3(2.5)$ \\
\hline Soundness of sleep, mean (SD) & $4.0(2.7)$ & $3.2(2.2)$ \\
\hline \multicolumn{3}{|l|}{ Secondary outcomes: health } \\
\hline Anxiety, HADS $^{\mathrm{g}}$, mean (SD) & $4.8(3.2)$ & $6.7(2.5)$ \\
\hline Depression, CES-D ${ }^{\mathrm{h}}$, mean (SD) & $18.5(4.6)$ & $21.4(5.4)$ \\
\hline $\mathrm{QOL}^{\mathrm{i}}, \mathrm{EQ}-5 \mathrm{D}^{\mathrm{j}}$, mean $(\mathrm{SD})$ & $0.911(0.125)$ & $0.703(0.174)$ \\
\hline
\end{tabular}

${ }^{\mathrm{a}} \mathrm{ICBT}$ : internet-delivered computerized cognitive behavioral therapy.

${ }^{\mathrm{b}} \mathrm{UC}$ : usual care.

${ }^{\mathrm{c}}$ PSQI: Pittsburgh Sleep Quality Index.

${ }^{\mathrm{d}}$ SOL: sleep onset latency.

${ }^{\mathrm{e}}$ TST: total sleep time.

${ }^{\mathrm{NA}} \mathrm{\text {nnumberofawakenings. }}$

${ }^{\mathrm{g}}$ HADS: Hospital Anxiety and Depression Scale.

${ }^{\mathrm{h}}$ CES-D: Center for Epidemiologic Studies Depression Scale.

${ }^{\mathrm{i}} \mathrm{QOL}$ : quality of life.

${ }^{\mathrm{j}} \mathrm{EQ}-5 \mathrm{D}$ : EuroQol-5D. 
Table 3. Adjusted mean changes in the primary and secondary outcomes.

\begin{tabular}{|c|c|c|c|c|c|c|c|}
\hline \multirow[t]{2}{*}{ Changes from baseline } & \multicolumn{2}{|c|}{$\mathrm{ICBT}^{\mathrm{a}}+\mathrm{UC}^{\mathrm{b}}(\mathrm{n}=11)$} & \multicolumn{2}{|l|}{$\mathrm{UC}(\mathrm{n}=12)$} & \multicolumn{2}{|c|}{ Intergroup difference } & \multirow[t]{2}{*}{$P$ value } \\
\hline & $\begin{array}{l}\text { Least squares } \\
\text { mean }\end{array}$ & $95 \% \mathrm{CI}$ & $\begin{array}{l}\text { Least squares } \\
\text { mean }\end{array}$ & $95 \% \mathrm{CI}$ & Difference & $95 \% \mathrm{CI}$ & \\
\hline $\begin{array}{l}\text { Primary outcome, PSQI }{ }^{\mathrm{c}} \text {, } \\
\text { week } 6\end{array}$ & -6.11 & -7.45 to -4.78 & 0.40 & -0.83 to 1.63 & -6.51 & -8.15 to -4.87 & $<.001$ \\
\hline \multicolumn{8}{|l|}{ Secondary outcomes } \\
\hline \multicolumn{8}{|l|}{ PSQI } \\
\hline Week 3 & -2.66 & -3.63 to -1.69 & 0.45 & -0.45 to 1.34 & -3.10 & -4.29 to -1.92 & $<.001$ \\
\hline Week 12 & -6.40 & -8.05 to -4.75 & 0.44 & -1.11 to 1.99 & -6.84 & -8.90 to 4.77 & $<.001$ \\
\hline \multicolumn{8}{|l|}{ SOL $^{d}$, minute } \\
\hline Week 3 & -10.82 & -19.58 to -2.06 & 3.25 & -5.00 to 11.49 & -14.07 & -24.97 to -3.16 & .01 \\
\hline Week 6 & -27.01 & -34.83 to -19.19 & 4.64 & -2.73 to 12 & -31.65 & -41.39 to -21.91 & $<.001$ \\
\hline Week 12 & -29.32 & -38.90 to -19.74 & 6.47 & -2.73 to 15.66 & -35.79 & -47.88 to -23.70 & $<.001$ \\
\hline \multicolumn{8}{|l|}{ TST $^{\mathrm{e}}$, hour } \\
\hline Week 3 & 0.49 & 0.13 to 0.86 & 0.07 & -0.27 to 0.41 & 0.43 & -0.03 to -0.88 & .06 \\
\hline Week 6 & 0.58 & 0.03 to 1.13 & -0.08 & -0.59 to 0.43 & 0.66 & -0.02 to 1.34 & .06 \\
\hline Week 12 & 0.49 & -0.08 to 1.05 & -0.05 & -0.59 to 0.48 & 0.54 & -0.17 to 1.25 & .13 \\
\hline \multicolumn{8}{|l|}{ Sleep efficiency, \% } \\
\hline Week 3 & 4.65 & 0.59 to 8.72 & -3.72 & -7.45 to 0.01 & 8.37 & 3.44 to 13.31 & .002 \\
\hline Week 6 & 13.24 & 8.67 to 17.81 & -4.68 & -8.87 to -0.48 & 17.92 & 12.37 to 23.47 & $<.001$ \\
\hline Week 12 & 13.32 & 8.68 to 17.97 & -7.00 & -11.37 to -2.63 & 20.32 & 14.55 to 26.1 & $<.001$ \\
\hline \multicolumn{8}{|l|}{$\mathbf{N A} \mathbf{f}^{\mathbf{f}}$} \\
\hline Week 3 & -0.53 & -1.17 to 0.12 & 0.61 & 0.01 to 1.21 & -1.14 & -1.93 to -0.34 & .008 \\
\hline Week 6 & -2.04 & -2.83 to -1.26 & 0.17 & -0.55 to 0.89 & -2.22 & -3.18 to -1.25 & $<.001$ \\
\hline Week 12 & -1.95 & -2.81 to -1.08 & 0.05 & -0.77 to 0.87 & -2.00 & -3.08 to -0.91 & $<.001$ \\
\hline \multicolumn{8}{|l|}{ Refreshment } \\
\hline Week 3 & 0.53 & -0.30 to 1.35 & -0.20 & -0.95 to 0.56 & 0.72 & -0.28 to 1.73 & .15 \\
\hline Week 6 & 2.09 & 0.67 to 3.51 & -0.49 & -1.79 to 0.81 & 2.58 & 0.84 to 4.31 & .006 \\
\hline Week 12 & 2.06 & 0.48 to 3.64 & -1.03 & -2.52 to 0.46 & 3.09 & 1.11 to 5.07 & .004 \\
\hline \multicolumn{8}{|l|}{ Soundness of sleep } \\
\hline Week 3 & 0.12 & -0.82 to 1.06 & -0.61 & -1.49 to 0.27 & 0.73 & -0.44 to 1.9 & .20 \\
\hline Week 6 & 2.76 & 1.25 to 4.28 & 0.30 & -1.11 to 1.72 & 2.46 & 0.58 to 4.34 & .01 \\
\hline Week 12 & 2.70 & 1.21 to 4.18 & -0.36 & -1.77 to 1.06 & 3.05 & 1.15 to 4.96 & .004 \\
\hline \multicolumn{8}{|l|}{ Anxiety, HADS $^{\mathrm{g}}$} \\
\hline Week 3 & -0.08 & -0.74 to 0.58 & 0.68 & 0.11 to 1.26 & -0.77 & -1.58 to 0.04 & .06 \\
\hline Week 6 & -0.83 & -1.62 to -0.04 & 1.17 & 0.48 to 1.85 & -1.99 & -2.96 to -1.02 & $<.001$ \\
\hline Week 12 & -0.95 & -1.98 to 0.08 & 1.45 & 0.54 to 2.37 & -2.40 & -3.70 to -1.11 & $<.001$ \\
\hline \multicolumn{8}{|l|}{ Depression, CES-D ${ }^{h}$} \\
\hline Week 3 & -2.46 & -4.34 to -0.59 & 0.74 & -1.00 to 2.47 & -3.20 & -5.56 to -0.84 & .01 \\
\hline Week 6 & -5.18 & -7.77 to -2.60 & 1.14 & -1.25 to 3.53 & -6.32 & -9.57 to -3.07 & $<.001$ \\
\hline Week 12 & -5.94 & -8.92 to -2.96 & 2.02 & -0.82 to 4.85 & -7.96 & -11.77 to -4.14 & $<.001$ \\
\hline QOL $^{\mathbf{i}}, \mathbf{E Q - 5 D ^ { \mathbf { j } }}$ & & & & & & & \\
\hline
\end{tabular}




\begin{tabular}{|c|c|c|c|c|c|c|c|}
\hline \multirow[t]{2}{*}{ Changes from baseline } & \multicolumn{2}{|c|}{$\mathrm{ICBT}^{\mathrm{a}}+\mathrm{UC}^{\mathrm{b}}(\mathrm{n}=11)$} & \multicolumn{2}{|l|}{$\mathrm{UC}(\mathrm{n}=12)$} & \multicolumn{2}{|c|}{ Intergroup difference } & \multirow[t]{2}{*}{$P$ value } \\
\hline & $\begin{array}{l}\text { Least squares } \\
\text { mean }\end{array}$ & $95 \% \mathrm{CI}$ & $\begin{array}{l}\text { Least squares } \\
\text { mean }\end{array}$ & $95 \% \mathrm{CI}$ & Difference & $95 \% \mathrm{CI}$ & \\
\hline Week 3 & -0.0065 & $\begin{array}{l}-0.0516 \text { to } \\
0.0386\end{array}$ & -0.0145 & -0.0546 to 0.0256 & 0.0079 & -0.0529 to 0.0688 & .78 \\
\hline Week 6 & 0.0487 & 0.0001 to 0.0972 & -0.0793 & $\begin{array}{l}-0.1225 \text { to } \\
-0.0361\end{array}$ & 0.128 & 0.0625 to 0.1935 & $<.001$ \\
\hline Week 12 & 0.059 & 0.003 to 0.115 & -0.0943 & $\begin{array}{l}-0.1457 \text { to } \\
-0.0429\end{array}$ & 0.1533 & 0.0759 to 0.2307 & $<.001$ \\
\hline
\end{tabular}

\author{
aICBT: internet-delivered computerized cognitive behavioral therapy. \\ ${ }^{\mathrm{b}} \mathrm{UC}$ : usual care. \\ ${ }^{c}$ PSQI: Pittsburgh Sleep Quality Index. \\ ${ }^{\mathrm{d}}$ SOL: sleep onset latency. \\ ${ }^{\mathrm{e}}$ TST: total sleep time. \\ ${ }^{f}$ NA: number of awakenings. \\ ${ }^{g}$ HADS: Hospital Anxiety and Depression Scale. \\ ${ }^{\mathrm{h}}$ CES-D: Center for Epidemiologic Studies Depression Scale. \\ ${ }^{\mathrm{i}} \mathrm{QOL}$ : quality of life. \\ ${ }^{\mathrm{j}} \mathrm{EQ}-5 \mathrm{D}$ : EuroQol-5D.
}

For the screening of insomnia, 5.5 is considered the optimal cut-off score of the PSQI [26,27]. We therefore set the threshold at a PSQI score of 5.5 to determine the remission of insomnia. At week 6, 36\% (4/11) of the patients in the ICBT plus UC group showed remission of insomnia with a PSQI score less than 5.5, whereas no UC group patient showed remission. At week $12,45 \%(5 / 11)$ of the patients in the ICBT plus UC group and no patient in the UC group showed remission with a PSQI score of less than 5.5. The remission rates at week 6 and 12 were significantly higher in the ICBT plus UC group compared with the UC group by Fisher exact test $(P<.05)$. There were no participants who could not complete the 5 lessons over a 6 -week period in the intervention group and did not get back to a cognitive behavioral therapist's weekly emails about their homework and progress. There were no reports of any adverse events in either group during the study.

\section{Discussion}

\section{Principal Findings}

This is the first RCT to examine the effectiveness of ICBT as a next step treatment for patients with insomnia who remain symptomatic despite drug treatment. Our findings demonstrate that the ICBT was effective as an adjunct to UC in reducing the severity of insomnia at week 6 immediately after the intervention. Moreover, the patients who received ICBT showed significant improvements at week 3 as a midpoint of the intervention and at week 12 of the follow-up period.

\section{Comparison With Prior Work}

A meta-analysis of RCTs including 14 records of 15 studies (1013 experimental group participants and 591 waiting list participants) showed that internet-based CBT for adults with insomnia is an effective treatment [28]. Except for being insomnia patients who remain symptomatic following treatment with a hypnotic in this study, the baseline clinical characteristics (age and sex) of our recruited patients in Japan are similar to those in Western countries. In their study of patients recruited from the general population, van Straten et al [25] reported that their guided ICBT for insomnia changed the mean PSQI score from 12.4 (SD 2.1) at pretreatment to 8.9 (SD 2.6) at week 6 post-treatment compared with a wait-list control group's score reduction from 11.7 (SD 2.2) to 11.6 (SD 2.5). In an investigation of patients with comorbid psychiatric diagnoses who were taking one or more psychotropic medications, Feuerstein et al [29] showed that their computer-based delivery of CBT for insomnia significantly improved the patients' PSQI scores compared with an active control group (sleep diary group). Our present findings regarding PSQI improvement seem comparable to these 2 studies even though the patient populations differ.

A meta-analysis of RCTs including 87 RCTs comparing 118 treatments (3724 patients) to nontreated controls (2579 patients) showed that face-to-face and ICBT for adults with insomnia are effective treatments [30]. In addition, that meta-analysis described between-group effect sizes of outcomes concerning sleep as follows: insomnia severity index (Hedges $g=0.98$ ), $\mathrm{SE}$ $(\mathrm{g}=0.71)$, PSQI $(\mathrm{g}=0.65)$, wake after sleep onset $(\mathrm{g}=0.63)$ and SOL $(g=0.57)$, NA $(g=0.29)$, and sleep quality $(g=0.40)$. The meta-analysis authors also mentioned that the smallest effect was on TST $(g=0.16)$ [30]. The various effect sizes on different sleep outcomes seem to be consistent with our finding that our ICBT program showed a remarkably large Hedges $g$ value for PSQI $(g=-3.36)$, SE $(g=2.36)$, SOL $(g=-1.80)$, and NA $(\mathrm{g}=-1.39)$, but not for TST $(\mathrm{g}=0.42)$; we calculated the between-group effect sizes at week 6 from baseline.

Moreover, Lancee et al [31] reported superior performance of face-to-face treatment relative to online treatment in their RCT comparing 3 conditions: guided online, face-to-face, and wait-list. In Japan, Yamadera et al [32] reported that face-to-face individual CBT for insomnia resulted in a PSQI improvement from 12.7 (SD 0.7) to 8.9 (SD 0.6) compared with the improvement because of group CBT from 12.2 (SD 0.5) to 10.1 
(SD 0.7). Okajima et al [14] reported that face-to-face individual CBT for pharmacological treatment-resistant chronic insomnia resulted in PSQI improvement from 13.59 (SD 3.25) to 8.10 (SD 2.95) compared with the improvement because of UC from 12.45 (SD 2.52) to 11.17 (SD 3.23). Our observation of PSQI improvement from 13.5 (SD 2.7) to 6.8 (SD 4.0) versus the improvement with UC from 13.9 (SD 4.0) to 13.9 (SD 4.0) seems to be comparable to the above 2 Japanese studies of face-to-face treatment, even though we used a guided online program. Further research is necessary to compare online CBT with face-to-face CBT, including cost-effectiveness and patients' preferences.

According to the algorithm in a new clinical practice guideline for the pharmacologic treatment of chronic insomnia in adults issued by the American Academy of Sleep Medicine [33], if pharmacologic treatment (short-term intermediate-acting benzodiazepine receptor agonists or ramelteon) does not improve the symptoms of an individual with chronic insomnia, clinicians should consider switching to another modality (ie, CBT) or combined treatment with CBT. The results of our present analyses suggest that the simple continuation of pharmacologic treatment was largely ineffective for our population of patients with insomnia and that clinicians should consider providing ICBT or referring patients to a CBT therapist if pharmacologic treatment is not sufficiently effective.
A meta-analysis of adherence to ICBT showed that the percentage of noncompleters of total ICBT intervention was $34.9 \%$ [34]. All participants in the ICBT plus UC group accomplished the total ICBT program in our study, one strength of this study is the low rate of dropout.

\section{Limitations}

This study has the following 5 limitations. First, we were unable to elucidate specific effects of the ICBT program because a psychological placebo group was not used to control for nonspecific factors. Second, the sample size was relatively small $(n=23)$. Third, the lack of 1-year follow-up data limits the generalizability of our conclusions. Larger- and longer-scale studies are necessary. Fourth, sleep estimates were based on subjective sleep diaries and PSQI scores, rather than on objective measures such as polysomnography. The use of both subjective and objective measures has been recommended [35,36]. Finally, Outcome assessors were not blinded; however, blinded outcome assessment is recommended in open label trials to reduce bias.

\section{Conclusions}

In conclusion, our results suggested that a 6-week ICBT program is an effective treatment for patients with insomnia who remain symptomatic following pharmacologic treatment.

\section{Acknowledgments}

This study was supported by part of the Grant-in-Aid for Scientific Research (B) from the Japan Society for the Promotion of Science (JSPS) (grant KAKENHI 17H04091 to Eiji Shimizu).

\section{Conflicts of Interest}

None declared.

\section{Multimedia Appendix 1 \\ CONSORT-EHEALTH checklist (V 1.6.1).}

[PDF File (Adobe PDF File), 2MB-Multimedia Appendix 1]

\section{References}

1. American Psychiatric Association. 5th ed. In: Diagnostic and statistical manual of mental disorders: DSM-5. Washington: American Psychiatric Publishing; May 22, 2013.

2. Ohayon MM. Epidemiology of insomnia: what we know and what we still need to learn. Sleep Med Rev 2002 Apr;6(2):97-111. [doi: 10.1053/smrv.2002.0186] [Medline: 12531146]

3. Lichstein KL, Durrence HH, Reidel BW, Taylor DJ, Bush AJ. Epidemiology of Sleep: Age, Gender, and Ethnicity. Mahwah, New York: Lawrence Erlbaum Associates Publishers; 2004:202-216.

4. Morphy H, Dunn KM, Lewis M, Boardman HF, Croft PR. Epidemiology of insomnia: a longitudinal study in a UK population. Sleep 2007 Mar;30(3):274-280. [Medline: 17425223 ]

5. Morin CM, Bélanger L, LeBlanc M, Ivers H, Savard J, Espie CA, et al. The natural history of insomnia: a population-based 3-year longitudinal study. Arch Intern Med 2009 Mar 09;169(5):447-453. [doi: 10.1001/archinternmed.2008.610] [Medline: 19273774]

6. Qaseem A, Kansagara D, Forciea MA, Cooke M, Denberg TD, Clinical Guidelines Committee of the American College of Physicians. Management of chronic insomnia disorder in adults: a clinical practice guideline from the American College of Physicians. Ann Intern Med 2016 Jul 19;165(2):125-133. [doi: 10.7326/M15-2175] [Medline: 27136449]

7. Vallières A, Morin CM, Guay B. Sequential combinations of drug and cognitive behavioral therapy for chronic insomnia: an exploratory study. Behav Res Ther 2005 Dec;43(12):1611-1630. [doi: 10.1016/j.brat.2004.11.011] [Medline: 16239154]

8. Morin AK. Strategies for treating chronic insomnia. Am J Manag Care 2006 May;12(8 Suppl):S230-S245 [FREE Full text] [Medline: $\underline{16686593}$ ] 
9. Morin CM, Benca RM. Chronic insomnia. Lancet 2012 Mar 24;379(9821):1129-1141. [doi: 10.1016/S0140-6736(11)60750-2] [Medline: 22265700]

10. Benca RM. Diagnosis and treatment of chronic insomnia: a review. Psychiatr Serv 2005 Mar;56(3):332-343. [doi: 10.1176/appi.ps.56.3.332] [Medline: 15746509]

11. International Narcotics Control Board. World Health Organization. 2010. Report of the International Narcotics Control Board on the Availability of Internationally Controlled Drugs: Ensuring Adequate Access for Medical and Scientific Purposes URL: http://apps.who.int/medicinedocs/en/m/abstract/Js21969en/ [accessed 2019-02-02] [WebCite Cache ID 75tUOiecq]

12. Schutte-Rodin S, Broch L, Buysse D, Dorsey C, Sateia M. Clinical guideline for the evaluation and management of chronic insomnia in adults. J Clin Sleep Med 2008 Oct 15;4(5):487-504 [FREE Full text] [Medline: 18853708]

13. Wilson SJ, Nutt DJ, Alford C, Argyropoulos SV, Baldwin DS, Bateson AN, et al. British Association for Psychopharmacology consensus statement on evidence-based treatment of insomnia, parasomnias and circadian rhythm disorders. J Psychopharmacol 2010 Nov;24(11):1577-1601. [doi: 10.1177/0269881110379307] [Medline: 20813762]

14. Okajima I, Nakamura M, Nishida S, Usui A, Hayashida K, Kanno M, et al. Cognitive behavioural therapy with behavioural analysis for pharmacological treatment-resistant chronic insomnia. Psychiatry Res 2013 Dec 15;210(2):515-521. [doi: 10.1016/j.psychres.2013.06.028] [Medline: 23953170]

15. Zachariae R, Lyby MS, Ritterband LM, O'Toole MS. Efficacy of internet-delivered cognitive-behavioral therapy for insomnia-a systematic review and meta-analysis of randomized controlled trials. Sleep Med Rev 2016 Dec;30:1-10. [doi: 10.1016/j.smrv.2015.10.004] [Medline: 26615572]

16. Sato D, Yoshinaga N, Nagai E, Hanaoka H, Sato Y, Shimizu E. Randomised controlled trial on the effect of internet-delivered computerised cognitive-behavioural therapy on patients with insomnia who remain symptomatic following hypnotics: a study protocol. BMJ Open 2018 Dec 30;8(1):e018220 [FREE Full text] [doi: 10.1136/bmjopen-2017-018220] [Medline: 29382675]

17. Carpenter JS, Andrykowski MA. Psychometric evaluation of the Pittsburgh Sleep Quality Index. J Psychosom Res 1998 Jul;45(1):5-13. [doi: 10.1016/S0022-3999(97)00298-5] [Medline: 9720850]

18. Doi Y, Minowa M, Uchiyama M, Okawa M, Kim K, Shibui K, et al. Psychometric assessment of subjective sleep quality using the Japanese version of the Pittsburgh Sleep Quality Index (PSQI-J) in psychiatric disordered and control subjects. Psychiatry Res 2000 Dec 27;97(2-3):165-172. [doi: 10.1016/S0165-1781(00)00232-8] [Medline: 11166088]

19. Yoshinaga N, Niitsu T, Hanaoka H, Sato Y, Ohshima F, Matsuki S, et al. Strategy for treating selective serotonin reuptake inhibitor-resistant social anxiety disorder in the clinical setting: a randomised controlled trial protocol of cognitive behavioural therapy in combination with conventional treatment. BMJ Open 2013;3(2):e002242 [FREE Full text] [doi: 10.1136/bmjopen-2012-002242] [Medline: 23408078]

20. Yoshinaga N, Matsuki S, Niitsu T, Sato Y, Tanaka M, Ibuki H, et al. Cognitive behavioral therapy for patients with social anxiety disorder who remain symptomatic following antidepressant treatment: a randomized, assessor-blinded, controlled trial. Psychother Psychosom 2016;85(4):208-217 [FREE Full text] [doi: 10.1159/000444221] [Medline: 27230862]

21. EuroQol Group. EuroQol--a new facility for the measurement of health-related quality of life. Health Policy 1990 Dec;16(3):199-208. [doi: 10.1016/0168-8510(90)90421-9] [Medline: 10109801]

22. Tsuchiya A, Ikeda S, Ikegami N, Nishimura S, Sakai I, Fukuda T, et al. Estimating an EQ-5D population value set: the case of Japan. Health Econ 2002 Jun;11(4):341-353. [doi: 10.1002/hec.673] [Medline: 12007165]

23. Manca A, Hawkins N, Sculpher MJ. Estimating mean QALYs in trial-based cost-effectiveness analysis: the importance of controlling for baseline utility. Health Econ 2005 May;14(5):487-496. [doi: 10.1002/hec.944] [Medline: 15497198]

24. Seki Y, Nagata S, Shibuya T, Yoshinaga N, Yokoo M, Ibuki H, et al. A feasibility study of the clinical effectiveness and cost-effectiveness of individual cognitive behavioral therapy for panic disorder in a Japanese clinical setting: an uncontrolled pilot study. BMC Res Notes 2016 Oct 07;9(1):458 [FREE Full text] [doi: 10.1186/s13104-016-2262-5] [Medline: 27717407]

25. van Straten A, Emmelkamp J, de Wit J, Lancee J, Andersson G, van Someren EJ, et al. Guided internet-delivered cognitive behavioural treatment for insomnia: a randomized trial. Psychol Med 2014 May;44(7):1521-1532. [doi:

10.1017/S0033291713002249] [Medline: 24001364]

26. Buysse DJ, Reynolds CF, Monk TH, Berman SR, Kupfer DJ. The Pittsburgh Sleep Quality Index: a new instrument for psychiatric practice and research. Psychiatry Res 1989 May;28(2):193-213. [doi: 10.1016/0165-1781(89)90047-4] [Medline: 2748771]

27. Backhaus J, Junghanns K, Broocks A, Riemann D, Hohagen F. Test-retest reliability and validity of the Pittsburgh Sleep Quality Index in primary insomnia. J Psychosom Res 2002 Sep;53(3):737-740. [doi: 10.1016/S0022-3999(02)00330-6] [Medline: $\underline{\text { 12217446] }}$

28. Ye YY, Chen NK, Chen J, Liu J, Lin L, Liu YZ, et al. Internet-based cognitive-behavioural therapy for insomnia (ICBT-i): a meta-analysis of randomised controlled trials. BMJ Open 2016 Dec 30;6(11):e010707 [FREE Full text] [doi: 10.1136/bmjopen-2015-010707] [Medline: 27903557]

29. Feuerstein S, Hodges SE, Keenaghan B, Bessette A, Forselius E, Morgan PT. Computerized cognitive behavioral therapy for insomnia in a community health setting. J Clin Sleep Med 2017 Feb 15;13(2):267-274 [FREE Full text] [doi:

10.5664/jcsm.6460] [Medline: 27784409] 
30. van Straten A, van der Zweerde T, Kleiboer A, Cuijpers P, Morin CM, Lancee J. Cognitive and behavioral therapies in the treatment of insomnia: a meta-analysis. Sleep Med Rev 2018 Dec;38:3-16. [doi: 10.1016/j.smrv.2017.02.001] [Medline: 28392168]

31. Lancee J, van Straten A, Morina N, Kaldo V, Kamphuis JH. Guided online or face-to-face cognitive behavioral treatment for insomnia: a randomized wait-list controlled trial. Sleep 2016 Jan 01;39(1):183-191 [FREE Full text] [doi: 10.5665/sleep.5344] [Medline: 26414893]

32. Yamadera W, Sato M, Harada D, Iwashita M, Aoki R, Obuchi K, et al. Comparisons of short-term efficacy between individual and group cognitive behavioral therapy for primary insomnia. Sleep Biol Rhythms 2013 Jul;11(3):176-184 [FREE Full text] [doi: 10.1111/sbr.12019] [Medline: 24098091]

33. Sateia MJ, Buysse DJ, Krystal AD, Neubauer DN, Heald JL. Clinical practice guideline for the pharmacologic treatment of chronic insomnia in adults: an American Academy of Sleep Medicine clinical practice guideline. J Clin Sleep Med 2017 Feb 15;13(2):307-349 [FREE Full text] [doi: 10.5664/jcsm.6470] [Medline: 27998379]

34. van Ballegooijen W, Cuijpers P, van Straten A, Karyotaki E, Andersson G, Smit JH, et al. Adherence to Internet-based and face-to-face cognitive behavioural therapy for depression: a meta-analysis. PLoS One 2014;9(7):e100674 [FREE Full text] [doi: 10.1371/journal.pone.0100674] [Medline: 25029507]

35. Buysse DJ. Sleep health: can we define it? Does it matter? Sleep 2014 Jan 01;37(1):9-17 [FREE Full text] [doi: 10.5665/sleep.3298] [Medline: 24470692]

36. Buysse DJ, Thompson W, Scott J, Franzen PL, Germain A, Hall M, et al. Daytime symptoms in primary insomnia: a prospective analysis using ecological momentary assessment. Sleep Med 2007 Apr;8(3):198-208 [FREE Full text] [doi: 10.1016/j.sleep.2006.10.006] [Medline: 17368098]

\author{
Abbreviations \\ ACP: American College of Physicians \\ ANCOVA: analysis of covariance \\ CBT: cognitive behavioral therapy \\ CES-D: Center for Epidemiologic Studies Depression Scale \\ CONSORT: Consolidated Standards of Reporting Trials \\ EQ-5D: EuroQol-5D \\ HADS: Hospital Anxiety and Depression Scale \\ ICBT: internet-delivered computerized cognitive behavioral therapy \\ NA: number of awakenings \\ PSQI: Pittsburgh Sleep Quality Index \\ QALY: quality-adjusted life year \\ QOL: quality of life \\ RCT: randomized controlled trial \\ SE: sleep efficiency \\ SOL: sleep onset latency \\ TST: total sleep time \\ UC: usual care
}

Edited by G Eysenbach; submitted 04.11.18; peer-reviewed by Y Minabe, N Siriwardena; comments to author 05.12.18; revised
version received 19.12.18; accepted 21.12.18; published 11.04.19
Please cite as:
Sato D, Yoshinaga N, Nagai E, Nagai K, Shimizu E
Effectiveness of Internet-Delivered Computerized Cognitive Behavioral Therapy for Patients With Insomnia Who Remain Symptomatic
Following Pharmacotherapy: Randomized Controlled Exploratory Trial
J Med Internet Res 2019;21(4):e12686
URL: $\underline{\text { http://www.jmir.org/2019/4/e12686/ }}$
doi: $\underline{10.2196 / 12686}$
PMID: $\underline{30973344}$

(CDaisuke Sato, Naoki Yoshinaga, Eiichi Nagai, Kazue Nagai, Eiji Shimizu. Originally published in the Journal of Medical Internet Research (http://www.jmir.org), 11.04.2019. This is an open-access article distributed under the terms of the Creative Commons Attribution License (https://creativecommons.org/licenses/by/4.0/), which permits unrestricted use, distribution, and reproduction in any medium, provided the original work, first published in the Journal of Medical Internet Research, is properly 
cited. The complete bibliographic information, a link to the original publication on http://www.jmir.org/, as well as this copyright and license information must be included. 